\title{
On the Region for the Application of Passive Damping Treatment and Loss Factor Enhancement
}

\author{
Thomas K. Joseph \\ Structures Group, ISRO Satellite Centre, Airport Road, Bangalore 560017, India.
}

K. Renji

Advanced Technology Development Group, ISRO Satellite Centre, Airport Road, Bangalore 560017, India.

\author{
Kartik Venkatraman \\ Department of Aerospace Engineering, Indian Institute of Science, Bangalore 560012, India.
}

\begin{abstract}
(Received 14 September 2017; accepted 13 March 2018)
The loss factor of a structure is significantly improved by using constrained damping treatment. For a mass efficient design, the damping material is to be applied at suitable locations. The studies reported in literature use the modal strain energy distribution in the viscoelastic material or the strain energy distribution in the base structure as tools to arrive at these suitable locations for the damping treatment. It is shown here that the regions identified through the above criteria need not be suitable for certain bending modes of vibration. A new approach is proposed in which the strain in the viscoelastic material and the angle of flexure are shown to be more reliable in arriving at the locations for the damping treatment. Providing damping layers at identified locations using these parameters results in significant loss factors with minimal added mass.
\end{abstract}

\section{INTRODUCTION}

Passive damping treatment has great importance in vibration control applications. A typical configuration consists of a basic structure to which one or more layers of a viscoelastic damping material are attached with possibly additional metal plates as constraining layers. Such systems essentially result in a composite labour, where the basic structure contributes the necessary stiffness and strength while the damping material dissipates vibration energy. Such treatments provide high damping capability over a wide frequency range and can easily be applied even to existing structures.

Typical materials used for passive damping treatment are viscoelastic in nature. Their loss factors can be as high as 1.0, compared to the loss factor of 0.01 , for bare aerospace structures. It is important to note that, though the loss factor of the viscoelastic material can be as high as 1.0, the loss factor of the composite structure is significantly low. The effective loss factor will be dependent on the type of deformation of the basic structure as well as that of the viscoelastic material. A suitable arrangement has to be configured to best utilize the dissipation in the damping layers.

Constrained layer damping is the most effective damping technique among the various types in practice for this study. In the constrained layer damping treatment, when the structure is subjected to cyclic bending, the metal layer constrains the viscoelastic material and forces it to deform in shear. The energy is thereby dissipated through the shear deformation of the viscoelastic material. ${ }^{1,2}$ Hence, the performance of the damping treatment is largely influenced the constraining layer. The constrained layer damping treatment can effectively provide large values of damping by suitable design of the constraining layer. It is desirable to have the constraining layer as stiff as possi- ble so as to introduce maximum shear strain in the viscoelastic layer. ${ }^{3,4}$ Providing damping layers throughout the structure results in a large mass penalty, especially due to the constraining layer. Therefore, partial damping treatment is generally employed. The loss factor with partial damping treatment will be lesser than that with the full damping treatment. However, the partial treatment provides the loss factor with minimum mass penalties.

There are a few studies reported on the loss factors of structures with partially treated damping layers. Nokes and Nelson obtained the loss factor of a partially treated beam. ${ }^{5}$ Dewa et al. used modal loss factors to estimate the loss factor of a partially covered five layered beam with alternate elastic and viscoelastic layers. ${ }^{6}$ Loss factor enhancement in a structure by limiting the constraining layer to appropriate lengths was analysed by Plunkett and Lee. ${ }^{7}$ Though loss factors of partially treated structures are obtained in several works, it is still unclear in literature as to which parameters will be influential and used to select the suitable location for providing the damping layer. Johnson and Kienholz used model strain energy distribution in the viscoelastic material to assess a suitable location for damping treatment. ${ }^{8}$ In many other studies modal strain energy in the base structure is used to decide the region of application. ${ }^{9-11}$ Both these methods have limitations. These are investigated in this work and a new approach is proposed.

For any such investigation a mathematical model is essential. Several approaches are in use to describe the behaviour of viscoelastic material used for damping treatment. Of these, the analysis developed by Ross-Kerwin-Ungar (RKU) has been widely used. ${ }^{12}$ They developed a model for the prediction of the loss factor of a simply-supported beam and plate with damping layers. Approximations are suggested for other 
boundary conditions depending on the mode shape of the system. When constrained layer damping treatment is applied to complex structures, the theoretical estimation of the loss factor of the composite structure is more involved if the above formulation is followed. In such cases, finite element method (FEM) is more convenient. The finite element method has been widely used in the structural dynamic analysis of constrained viscoelastic laminates. ${ }^{13-15}$ Other than the finite element method, there are several methods used for the numerical evaluation of the loss factor of a structure. Castel et al. used power flow parameters to determine the loss factor of the structure with a passive constrained layer damping patch. ${ }^{16}$ Shorter represented damping in spectral element representation of the wave motion. ${ }^{17}$ Another numerical technique is the wave finite element method in which the wave motion equations are solved using finite elements. Mace et al. applied the wave finite element method to a one dimensional structure and Manconi and Mace demonstrated it for a two dimensional structure. ${ }^{18,19} \mathrm{In}$ these methods, frequency-averaged loss factors are obtained and not the loss factor for a particular mode. Also, the boundary effects are not included, as it assumes a simply supported edge condition. Therefore, they are not suitable for the first few bending modes of a structure, but best suitable for higher order modes for which sufficient information on the frequencyaveraged loss factor exists. Hence in the present investigation, the finite element method is used in estimating the loss factor of the composite structure from the known loss factor values of the viscoelastic material.

Many studies reported in literature are related to the fundamental mode of vibration. Though the fundamental mode is of great concern, the higher vibration modes also assume importance in spacecraft structures as the excitation is present over a wide frequency range. In the case of a cantilever beam, that was used for many of the reported investigations, parameters, like the bending stress, shear stress, and strain energy in the viscoelastic material, show a maximum value at the same location that is close to the fixed end. ${ }^{8,9}$ Hence, it is possible to conclude on the parameters that will be used to decide the suitable locations of damping treatment based on the fundamental mode of vibration. Therefore, in the present study, emphasis is given to the second mode of vibration.

In this work, it is shown that the application of damping treatment in the region identified by those in earlier researches need not result in an improved loss factor for certain bending modes. An alternate approach to arrive at the regions for the application of damping treatment is presented. It is shown, that using the new approach the limitation of the existing methodology can be overcome. The methodology is demonstrated through finite element simulations as well as experiments.

\section{THEORETICAL AND EXPERIMENTAL DETERMINATION OF LOSS FACTOR}

Though the loss factor of the viscoelastic material is significant, the effective loss factor of the structure is very small. Here, the theoretical and experimental determination of the loss factor of the structure is explained, and then the methodology is demonstrated. The loss factor is a measure of the energy dissipated.

\subsection{Theoretical Estimation}

The loss factors of simple structures like beams and plates, which have simple boundary conditions from the known values of loss factors of the damping materials, can be estimated using closed-form expressions. For other complex structural elements, the finite element method is generally used. ${ }^{13-15}$ It is not the loss factor of the material that is of importance but the loss factor of the structure in a particular mode of vibration, called the modal loss factor, which is the parameter of interest. Modal strain energy method is used in determining the loss factor. The modal loss factor in the $r$ th mode can be expressed as: ${ }^{20}$

$$
\eta_{v}^{r}=\eta_{v} \frac{V_{v}^{r}}{V^{r}}
$$

In Eq. (1), $V_{v}^{r}$ is the modal strain energy of the viscoelastic material, and $V^{r}$ is the total strain energy in the $r$ th mode. Here, $\eta_{v}$ is the material loss factor of the viscoelastic layer, and $\eta_{v}^{r}$ is the modal loss factor in the $r$ th mode. This method assumes proportional damping. In other words, the damping thus estimated is to be interpreted as equivalent proportional damping. Even if the damping is not proportional, the energy dissipated in the damping layers is considered and equated to the energy dissipated if it were proportional damping. Hence the assumption of proportional damping is not expected to change the result.

\subsection{Experimental Loss Factor}

Experimentally, the loss factor of the structure can be determined using the half-power bandwidth method. In this approach, the frequency response function of the structure is first determined. From the half-power points in the frequency response function, the loss factor is estimated using the relation:

$$
\eta^{r}=\frac{\Delta f^{r}}{f_{n}^{r}}
$$

where $\Delta f$ is the half-power bandwidth of the natural mode having natural frequency $f_{n}$. The half-power bandwidth method is a well-established technique in determining the modal loss factors. ${ }^{21}$ The accuracy of the damping factor derived through the half-power bandwidth method depends on the damping factor itself. If the damping factor is very low, the derived damping factor will be close to the actual damping factor. For example, it can be shown that for a damping factor of 0.5 , the half-power bandwidth method gives a value of about 0.625 , causing an error of $25 \%$. Since, the maximum damping factor in the present work is about 0.1 and the derived damping factor will be about 0.101 , the half-power bandwidth method is considered as the most suitable method.

\subsection{Demonstration of the Methodology}

The loss factor of a typical beam with constrained viscoelastic material is determined experimentally and compared with the theoretically estimated loss factor. Commercially available $3 \mathrm{M}^{\mathrm{TM}} 242 \mathrm{~F} 02$ ultra-pure viscoelastic damping polymer with a thickness of $0.0508 \mathrm{~mm}$ is used in the present study. Details of the storage modulus and the loss factor of the viscoelastic material as provided by the manufacturer are given in Fig. 1. 


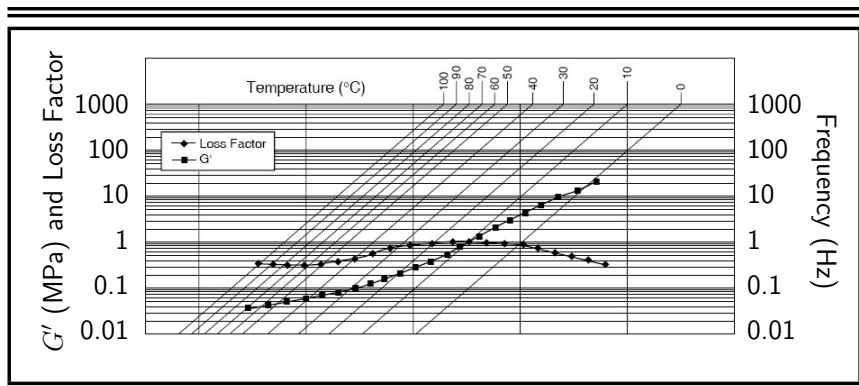

Figure 1. Nomogram of $3 \mathrm{M}^{\mathrm{TM}} 242 \mathrm{~F} 02$ viscoelastic damping polymer.

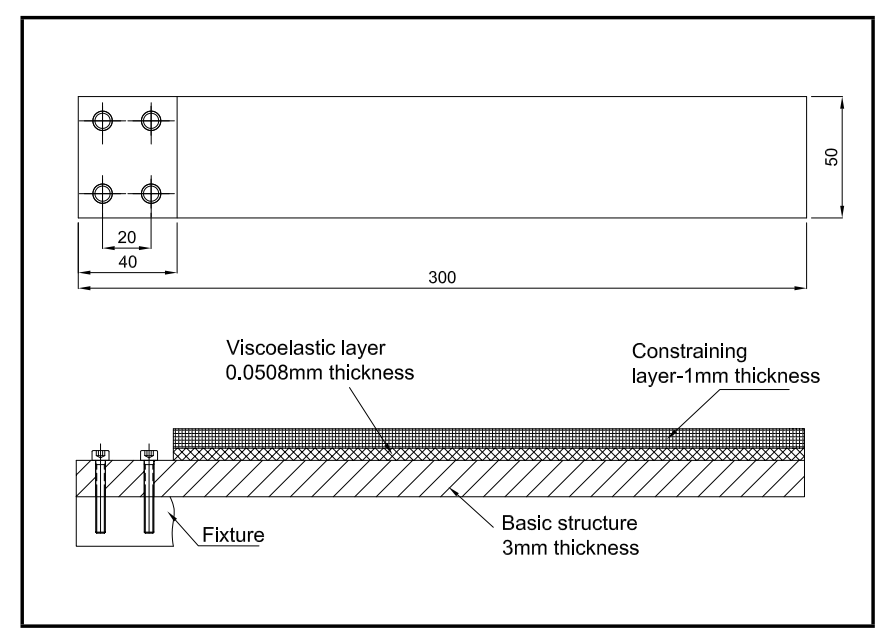

Figure 2. Geometrical details of the beam with constrained viscoelastic layer.

These parameters change with the temperature and frequency. Properties corresponding to $25^{\circ} \mathrm{C}$ are considered. There are two frequency ranges of interest, which correspond to the frequencies of the first and the second mode. In the frequency range of $5-100 \mathrm{~Hz}$, the loss factor is about 0.9 . The shear storage modulus is $2.0 \times 10^{6} \mathrm{~N} / \mathrm{m}^{2}$ and the extensional storage modulus is $6.0 \times 10^{6} \mathrm{~N} / \mathrm{m}^{2}$. In the second frequency range centred around $250 \mathrm{~Hz}$, the loss factor is 0.9 . The shear storage modulus is about $5.0 \times 10^{6} \mathrm{~N} / \mathrm{m}^{2}$ and the corresponding extensional storage modulus is $15.0 \times 10^{6} \mathrm{~N} / \mathrm{m}^{2}$. The value of the Poisson's ratio is considered to be 0.49 in both the frequency ranges.

A cantilever beam with constrained layer damping treatment as shown in Fig. 2 was used for the experiment. The base structure made of aluminium has a thickness of $3 \mathrm{~mm}$ with a mass of $126 \mathrm{~g}$. The constraining layer is made of aluminium and has a thickness of $1 \mathrm{~mm}$. The dimensions and other details of the construction are shown in Fig. 2. The mass of the viscoelastic layer is $0.52 \mathrm{~g}$ while that of the constraining layer is $36.4 \mathrm{~g}$.

The beam was mounted on a shaker, and a sinusoidal excitation, having an amplitude of acceleration of $0.2 \mathrm{~g}$, was enforced at the interface. The frequency of excitation was varied from 5 to $300 \mathrm{~Hz}$ and a swept sine test was performed with a sweep rate of 2 octaves per minute. The acceleration responses were measured at the representative locations. From the frequency response function shown in Fig. 3 the loss factors were determined using Eq. (2) and the results are given in Table 1.

The loss factor determined experimentally is the loss factor of the composite. This implies that the loss factor is due to the base structure and the viscoelastic material. Therefore, to interpret the results, the loss factor of the base structure should be

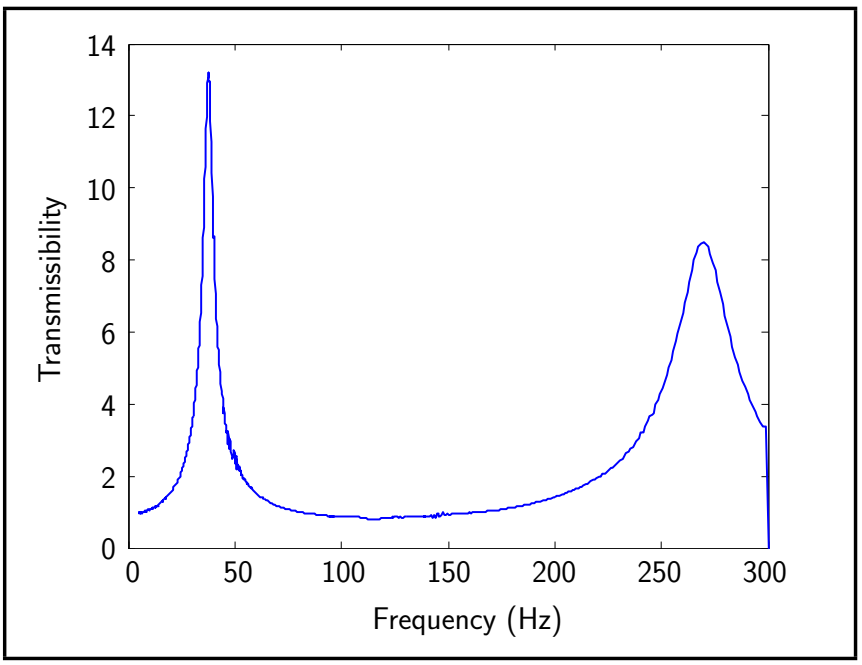

Figure 3. Frequency response function of the beam with constrained layer damping treatment.

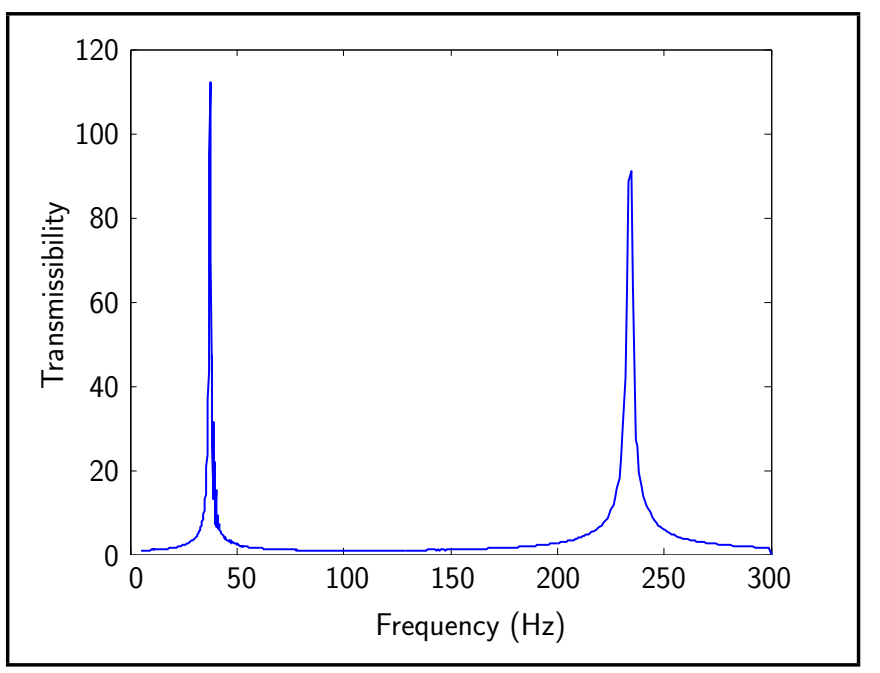

Figure 4. Frequency response function for the base-structure.

known. The frequency response function of the base structure from the experiment is given in Fig. 4. The modal loss factors of the base structure, without the damping treatment, were obtained experimentally and are given in Table 1 . The modal loss factor of the beam obtained from the experiment is much higher than the loss factor of the aluminum material reported in literature. This is expected as the loss factor of the beam, is not due to the material loss factor alone but is also attributed to the joint at the fixed-end support of the cantilever. This is the reason for obtaining the loss factor of the base structure through an experiment instead of considering the values provided in literature.

The loss factors due to the passive damping treatment are theoretically determined from the modal strain energies using Eq. (1). The well-known finite element software MSC/PATRAN $^{\circledR}$ and MSC/NASTRAN ${ }^{\circledR}$ was used as the tool for the free vibration analysis and for determining the modal strain energies. In the finite element model, the beam and the constraining layers were modelled using 4-noded shell elements. The size of the $2 \mathrm{D}$ element was $2.5 \mathrm{~mm} \times 1.25 \mathrm{~mm}$. The number of elements considered along the length was 120 and along the width was 40 . The viscoelastic material was modelled with 8-noded hexagonal elements. There were two 
elements in the thickness direction of the viscoelastic layer. In the finite element model, one end of the beam was fixed.

The modal loss factors were computed using Eq. (1) and are given in Table 1. It is to be noted that they were computed from the free vibration characteristics. Due to the presence of loss factor, the modes were complex in nature. The complex modal vector and the real valued modal vector were compared and found to be agreeable, probably because the loss factor was not that high, the maximum being 0.1 . Since the strain energies computed with real modes were identical to those computed with complex modes, only the strain energies computed with the real modes are presented and discussed further.

Note that the loss factor predicted using Eq. (1) is due to the dissipation by the viscoelastic material alone. But the measured loss factor includes the dissipation due to the viscoelastic material and the base structure. The loss factor of the composite structure was determined using the measured modal loss factor of the base structure and theoretically estimated loss factor of the viscoelastic layer using the relation:

$$
\eta^{r}=\frac{\eta_{v} V_{v}^{r}+\eta_{s} V_{s}^{r}}{V^{r}}=\eta_{v}^{r}+\eta_{s}^{r}
$$

In Eq. (3), $V_{s}^{r}$ is the strain energy of the base structure in the $r$ th mode, and $\eta_{s}$ is the material loss factor of the base structure. These results are compared with the experimental results listed in Table 1.

The loss factors predicted compared well with the experimental results. The match was very good for the first mode, but they were not that close for the second mode. The loss factor of the structure is dependent on the loss factor and the shear modulus of the viscoelastic material. These properties of the basic viscoelastic material used were not measured values but the values provided by the manufacturer. Any error in these properties can lead to an error in the estimated loss factor of the structure.

It is to be pointed out here that the loss factor estimated is the modal loss factor (i.e. applicable to each mode). They were obtained from the free vibration characteristics. However, the loss factors were measured by exciting the structure at one end, (i.e. from base excited response characteristics, which is a superposition of modal responses). Since the modes are wellseparated, well beyond half-power bandwidth, responses near the resonance frequencies behave like independent modes and the measured loss factors are the modal loss factors.

The analytical and experimental procedures outlined above for determining the loss factors are adopted in the studies that follow.

\section{REGION FOR APPLICATION DAMPING TREATMENT}

Though the damping can be improved by the application of constrained viscoelastic layer, it results in an increase in the mass mainly due to the constraining layer. This may be acceptable for ground applications, but it is of concern for use in spacecrafts. In the example given previously, the increase in mass with the addition of the constrained layer damping treatment is around $30 \%$. For aerospace structures in general, and for spacecraft structures in particular, this is not an efficient design. The goal of an effective damping treatment is thus to add

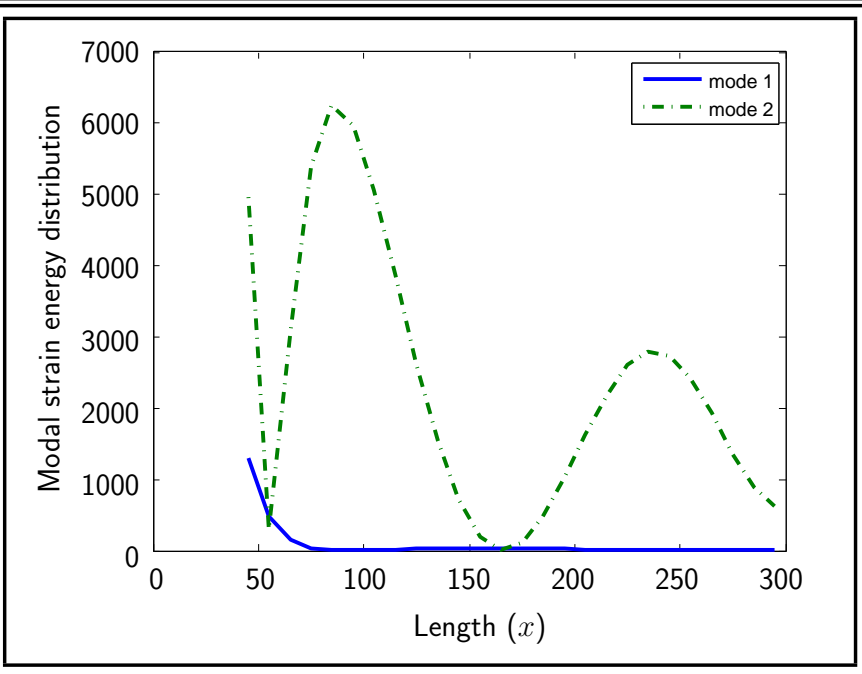

Figure 5. Modal strain energy distribution in the viscoelastic material along the length of the beam.

viscoelastic material in such a manner and at such locations so as to dissipate large vibrational energy with the least possible addition of mass. Therefore, it is necessary to suitably locate the damping layer with the objective of minimizing the added mass.

It is to be noted that the loss factor thus obtained will be less than the loss factor obtained if the damping treatment is applied on the entire surface of the structure. But by selecting suitable locations for its application, the increase in the mass is minimized.

\subsection{Existing Approaches}

In some works reported in literature, the modal strain energy distribution in the viscoelastic material is used as a figure of merit to arrive at the optimum location for the damping treatment. Consider the example discussed earlier. ${ }^{8}$ The modal strain energy distribution in the viscoelastic material along the length of the beam is shown in Fig. 5.

Consider the second mode of vibration. The loss factor, if the viscoelastic material is present along the full length of the beam, that is $260 \mathrm{~mm}$ (Fig. 2), is 0.050 . Figure 5 shows that the strain energy in the viscoelastic material is quite significant in the region $70-120 \mathrm{~mm}$ and $220-260 \mathrm{~mm}$. As the viscoelastic material is to be applied where the strain energy in the viscoelastic material is significant, it has to be applied in the region $70-120 \mathrm{~mm}$ and $220-260 \mathrm{~mm}$. The loss factor, if the viscoelastic material is present only in the above region, is computed as 0.012 , given in Table 2. It shows that the regions of application selected, based on the above parameters, are not appropriate.

In another study, the location for the viscoelastic material is selected based on the strain energy distribution in the base structure. ${ }^{9,10}$ In this method, the deformation of the viscoelastic material is not considered, though the dissipation is produced by the deformation of the viscoelastic material. The parameters involving the viscoelastic material should have a role in deciding the region. This is absent when we use the strain energy distribution in the base structure alone as the criteria. One can have large strain in the base structure without much deformation in the viscoelastic layer. Therefore, the region identified by the strain energy distribution in the base structure 
Table 1. Modal loss factor for the beam having $1 \mathrm{~mm}$ constrained viscoelastic layer.

\begin{tabular}{||l|l|l|l|l|l|l|l||}
\hline $\begin{array}{l}\text { Mode } \\
\text { No. }\end{array}$ & $\begin{array}{l}\text { Mode } \\
\text { description }\end{array}$ & $\begin{array}{l}\text { Frequency } \\
(\mathbf{H z}) \\
\text { (composite) } \\
\text { Theory }\end{array}$ & $\begin{array}{l}\text { Frequency } \\
\text { (Hz) } \\
\text { (composite) } \\
\text { Experiment }\end{array}$ & $\begin{array}{l}\text { Modal loss } \\
\text { factor } \eta_{s}^{r} \\
\text { (base-structure) } \\
\text { Experiment }\end{array}$ & $\begin{array}{l}\text { Modal loss } \\
\text { factor } \eta_{v}^{r} \\
\text { (viscoelastic) } \\
\text { Theory }\end{array}$ & $\begin{array}{l}\text { Modal loss } \\
\text { factor } \\
\text { (composite) } \\
\text { Theory }\end{array}$ & $\begin{array}{l}\text { Modal loss } \\
\text { factor } \\
\text { (composite) } \\
\text { Experiment }\end{array}$ \\
\hline 1. & $\begin{array}{l}\text { 1st Bending } \\
\text { 2nd Bending }\end{array}$ & $\begin{array}{l}38.8 \\
2 .\end{array}$ & $\begin{array}{l}37.6 \\
270\end{array}$ & 0.021 & 0.091 & 0.112 & 0.116 \\
0.012 & 0.050 & 0.062 & 0.090 \\
\hline
\end{tabular}

Table 2. Loss factor in the second mode of the beam with partial constrained layer.

\begin{tabular}{|c|c|c||}
\hline & $\begin{array}{c}\text { Constrained layer } \\
\mathbf{4 0 - 3 0 0 ~} \mathbf{~ m m}\end{array}$ & $\begin{array}{c}\text { Constrained layer } \\
\mathbf{7 0 - 1 2 0} \mathbf{~ m m}, \\
\mathbf{2 2 0 - 2 6 0} \mathbf{~ m m}\end{array}$ \\
\hline loss & 0.050 & 0.012 \\
factor & & \\
\hline
\end{tabular}

is not suitable. In some specific cases, application of damping treatment in the region identified by this method may give an increased loss factor and hence one may conclude that use of strain energy in the basic structure itself can give a suitable result. However it is not logical to use strain energy in the basic structure alone since the parameter to decide the region of application does not consider any of the parameters involving deformation of the viscoelastic layer. Neglecting these parameters involving the viscoelastic material properties remain as the drawback of this method.

Therefore, a new approach where these shortcomings are overcome is necessary. The goal is to arrive at suitable locations for the damping treatment such that it is applied on a minimal region of the base structure with a maximum possible loss factor.

\subsection{An Improved Method}

The proposed method considers the deformations in the viscoelastic material, and it will be shown later that significant increase in loss factor can be realized by providing material in a small region.

It is shown in that the loss factor in the bending mode of vibration of a structure with constrained viscoelastic layer can be obtained as:

$$
\eta=\eta_{2} \frac{G_{2} d_{2} \gamma_{2}^{2}}{B k^{2} \theta^{2}}
$$

where $\eta_{2}$ is the loss factor of the viscoelastic material, $G_{2}$ is the storage shear modulus of the viscoelastic materialanother, $d_{2}$ is the thickness of the viscoelastic material, $\gamma_{2}$ is the shear strain in the viscoelastic material, $B$ is the flexural stiffness of the composite plate, $k$ is the bending wave number, and $\theta$ is the angle of flexure. ${ }^{4}$ A close examination of the equation shows that the parameters $\gamma$ and $\theta$ vary along the length of the beam whereas the other parameters do not.

From the above equation, it can be seen that the most effective location for the application of the viscoelastic material is where $\frac{\gamma}{\theta}$ is significant, which is the region having significant shear deformation in the viscoelastic material with the least angle of flexure in the base structure. This is because a larger $\frac{\gamma}{\theta}$ ensures significant energy dissipation in the viscoelastic layers with the least bending of the base structure. The $\theta$ should be least to produce significant relative motion in the viscoelastic

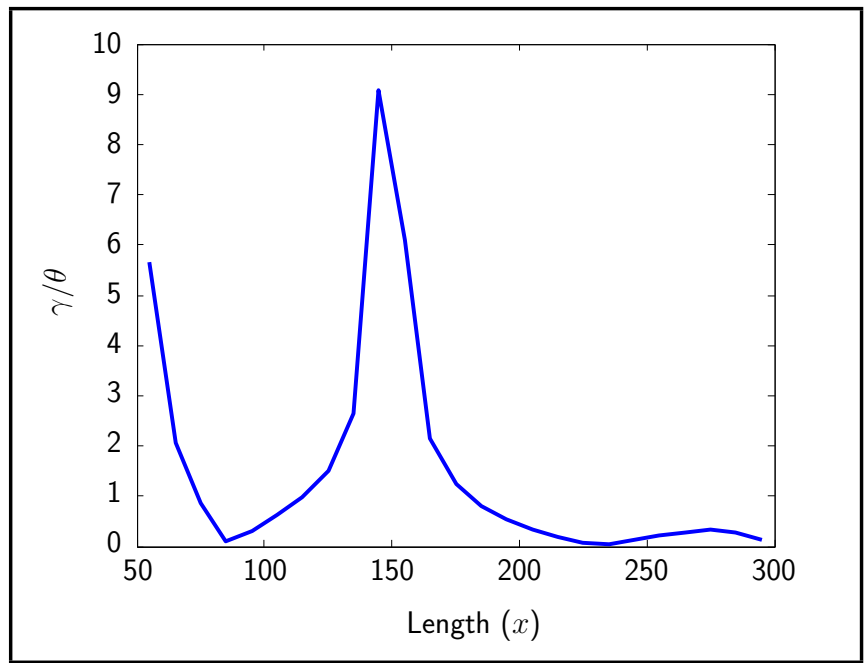

Figure 6. Variation of $\frac{\gamma}{\theta}$ along the length of the beam for the second mode.

Table 3. Loss factor in the second mode of the beam-based on $\frac{\gamma}{\theta}$.

\begin{tabular}{|c|c|c|c|}
\hline & $\begin{array}{c}\text { Constrained layer } \\
120-160 \mathrm{~mm}\end{array}$ & $\begin{array}{c}\text { Constrained layer } \\
120-160 \mathrm{~mm} \\
\text { (Composite) } \\
\text { Theory }\end{array}$ & $\begin{array}{c}\text { Constrained layer } \\
120-160 \mathrm{~mm} \\
\text { Experiment }\end{array}$ \\
\hline $\begin{array}{l}\text { loss } \\
\text { factor }\end{array}$ & 0.028 & 0.04 & 0.037 \\
\hline
\end{tabular}

layers. Energy dissipates due to relative motion. The loss factor is very much influenced by the boundary conditions, and the parameter $\frac{\gamma}{\theta}$ considers this as $\theta$ varies with boundary conditions. The variation of the parameter $\frac{\gamma}{\theta}$ along the length of the beam in the second mode of vibration of the example considered earlier is shown in Fig. 6.

Based on the above results, the suitable location for the application of the viscoelastic material is the region 120$160 \mathrm{~mm}$. The corresponding theoretically estimated loss factor is 0.028 , given in Table 3 . This is achieved with a constraining layer mass of $5.7 \mathrm{~g}$ compared to the base structure mass of $126 \mathrm{~g}$, which amounts to just $4.5 \%$ additional mass. If the damping layer is applied on the entire structure, the loss factor would have been 0.05 , but the added mass would be $37 \mathrm{~g}$.

When the region with the parameter $\frac{\gamma}{\theta}$ being high is selected for the application of the damping treatment, it is possible that it can show a very high value, singularity, when $\theta$ tends to zero. The parameter $\frac{\gamma}{\theta}$ can be very significant without $\gamma$ being significant and $\theta$ being very small. This can lead to wrong conclusions. Therefore, to use this parameter, careful interpretation of the results is required. The region that has to be looked for is the region having significant shear deformation in the viscoelastic material with least angle of flexure in the base structure, and not just $\frac{\gamma}{\theta}$ being high. Therefore, one needs to plot the variation of $\gamma$ as well as $\theta$. Figure 7 gives these details for the second mode of vibration. The parameters $\gamma$ and 


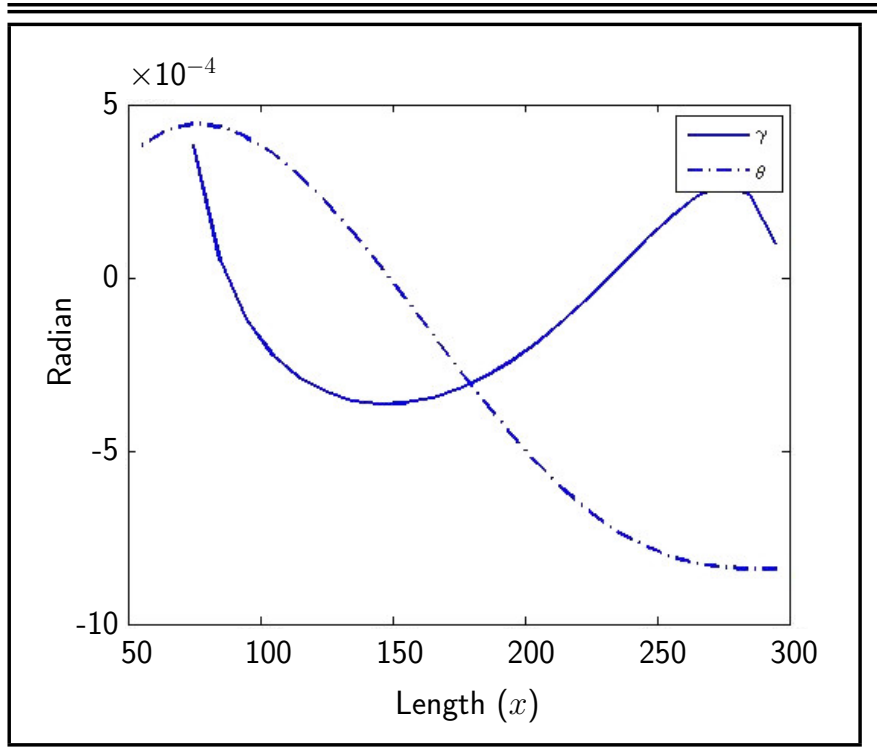

Figure 7. Variation of $\gamma$ and $\theta$ along the length of the beam (second mode).

$\theta$ are mass-normalized modal parameters and hence the values may appear very large or small. As we need to know only the variation along the length of the beam, it does not affect the result. It is seen that in the region of $120-160 \mathrm{~mm}$ the value of $\theta$ (Fig. 7) becomes zero. Consequently, $\frac{\gamma}{\theta}$ can have very large values. But it is also seen that $\gamma$ (Fig. 7) is also significant in this region. In other words, significant $\gamma$ is achieved in this region with a small value of $\theta$. Therefore, providing damping layers in the region of $120-160 \mathrm{~mm}$ would be the most preferred location for improving the loss factor. The method to be used is to use the parameter of $\frac{\gamma}{\theta}$ and locate the region where it is higher. One should also obtain the variation of $\gamma$ as well as $\theta$. Damping layers have to be applied in such regions where $\gamma$ is quite significant but $\theta$ is very small, $\frac{\gamma}{\theta}$ being high alone should not be the only criteria. At locations where $\theta$ is very small, if $\gamma$ is not significant, applying damping layers in such regions will not yield better damping though $\frac{\gamma}{\theta}$ can show significant values. Similarly, $\gamma$ being larger alone does not result in higher loss factor. It should be with a smaller value of $\theta$; otherwise, there will not be much energy dissipation. For example, though $\gamma$ is higher at the free end, $\theta$ is also higher and hence does not provide energy dissipation. Thus, one can restate the improved method as to select the region having significant shear deformation in the viscoelastic material $\gamma$ with the least angle of flexure in the base structure $(\theta)$ and not $\frac{\gamma}{\theta}$ being the highest.

In all the above discussions, the results of the second mode are considered. A similar exercise is carried out for the first mode. The variation of the parameter $\gamma$ and $\theta$ along the length of the beam are shown in Fig. 8. Based on these results, the viscoelastic material is applied in the region $40-80 \mathrm{~mm}$. The loss factor obtained is 0.054 as shown in Table 4. This is achieved with a constraining layer mass of $5.7 \mathrm{~g}$ compared to the base structure mass of $126 \mathrm{~g}$.

In the first mode of bending vibration, the optimum region for the application of constrained viscoelastic layers will be the same as per existing and the proposed approaches. Only, when the results of the second mode are considered, one can observe the differences between both methods. The method presented in this study provides a suitable location for the application of

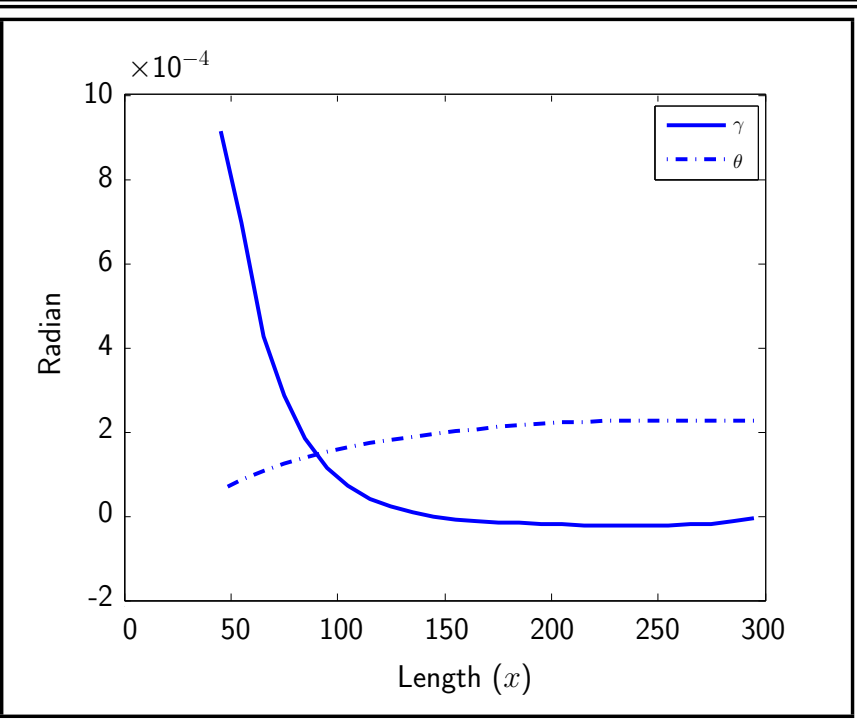

Figure 8. Variation of $\gamma$ and $\theta$ along the length of the beam (first mode).

Table 4. Loss factor in the first mode of the beam-based on $\frac{\gamma}{\theta}$.

\begin{tabular}{|c|c|c|}
\hline & $\begin{array}{c}\text { Constrained layer } \\
\mathbf{4 0 - 3 0 0}\end{array}$ & $\begin{array}{c}\text { Constrained layer } \\
\mathbf{4 0 - 8 0}\end{array}$ \\
\hline loss factor & 0.091 & 0.054 \\
\hline additional mass (\%) & 29.36 & 4.51 \\
\hline
\end{tabular}

the damping treatment for fundamental as well as for higher modes.

It is also possible that in some modes the region identified by the existing methodology may match with the region identified by the proposed method, and one may not find any need for the proposed method. But in most of the modes, the regions identified by these methods are different, and the application of the damping treatment in the region identified by the existing method does not result in improved loss factors. However, the proposed method does. Another example, given in section 4.2 , for a simply supported beam, illustrates this further. Even in the first mode of vibration, providing damping layers in the regions identified by the modal strain energy in the base structure does not result in an enhanced loss factor, but a significant loss factor is achieved if provided in regions identified by the proposed method.

The length of the viscoelastic material is decided based on the above criteria. The width of the layer is the width of the beam. As it is a one-dimensional structure, the width of the layer has to be the width of the beam. If we extend it to a twodimensional structure, one needs to apply this criteria along both directions to arrive at the size of the layer along each direction.

\section{DEMONSTRATION OF METHODOLOGY}

\subsection{Experimental Demonstration}

The above findings have been verified through experiments. The constrained passive damping was applied in the region $120-160 \mathrm{~mm}$ of the beam used in the previous experiment. The loss factor obtained experimentally was 0.037 , given in Table 3. The response function of the beam with the constrained layer damping in the region $120-160 \mathrm{~mm}$ of the beam is given in Fig. 9. Thus, the application of damping treatment 


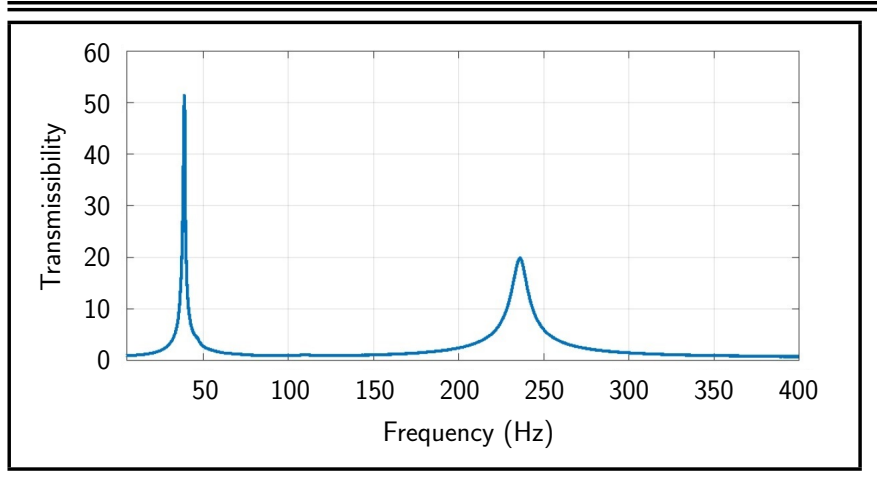

Figure 9. Frequency response function of the beam with constrained layer damping in the region $120-160 \mathrm{~mm}$.

in the region identified by the proposed method significantly increases the loss factor. The theoretically predicted loss factor due to the viscoelastic layer was 0.028 , and the loss factor of the composite structure was 0.040 . The predicted loss factor is in close agreement with the measured values.

It is seen that the use of the parameter $\frac{\gamma}{\theta}$ is much more efficient in arriving at suitable locations for the application of constrained viscoelastic layers than using the modal strain energy in the viscoelastic material. The parameter $\frac{\gamma}{\theta}$ depends on the mode of vibration, and hence, it has to be evaluated for each mode.

The region is selected based on the characteristics of the structure with full treatment. When a part of the damping treatment is removed, distribution of some parameters can change. As the parameter used for the selection of the region includes the shear angle in the viscoelastic layer, the information will be absent at all locations where the damping treatment is removed. Information will be available only at such locations where the treatment is still present. Whether the locations selected based on the characteristics of the fully treated structure are still suitable when the damping is applied partially can be inferred from the computed loss factor. If the partial treatment has modified the characteristics, significant loss factors would not have been achieved by the partial treatment.

\subsection{Other Boundary Conditions}

For the demonstration, we used a cantilevered beam. Though experimentally it is difficult to determine for other boundary conditions, it is possible to simulate the demonstration through numerical simulation. To substantiate the proposed method for other boundary conditions, it was demonstrated for a beam with simply supported boundary conditions. The loss factor computed with damping layer along the entire length of the simply supported beam was 0.03 . The strain energy distribution in the base structure is shown in Fig. 10. From Fig. 10, region $130-170 \mathrm{~mm}$ is the suitable location for the damping treatment which is based on the modal strain energy distribution in the base structure. The loss factor with damping treatment applied in the region 130-170 mm was 0.014 , which is much less.

Consider the variation of $\gamma$ in the viscoelastic material along the length of the beam, which is shown in Fig. 11. From Fig. 11, regions $0-40 \mathrm{~mm}$ and $260-300 \mathrm{~mm}$ are the optimum location for damping treatment, which is based on the variation of $\gamma$ in the viscoelastic material. The loss factor when damping

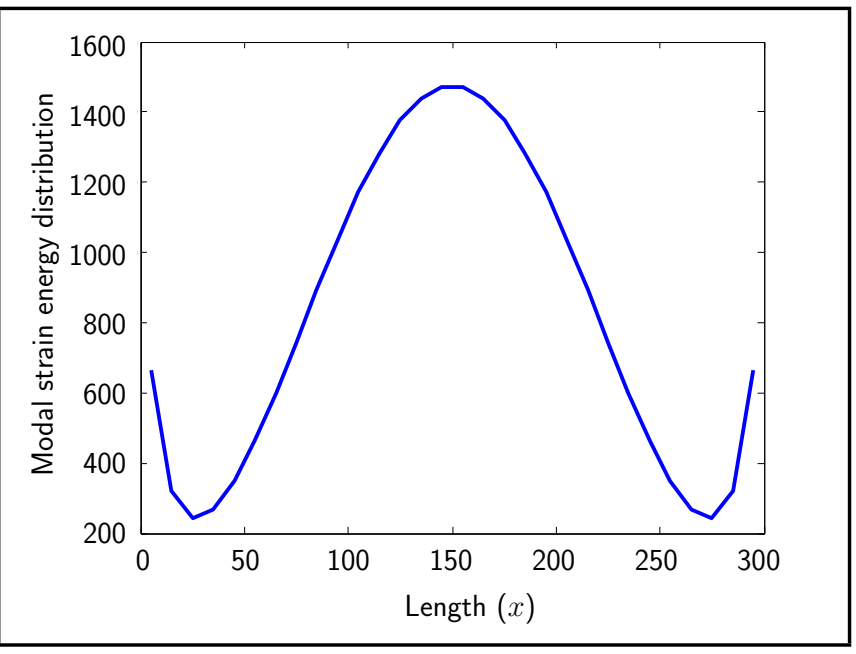

Figure 10. Modal strain energy distribution along the length of the simply supported beam (first mode).

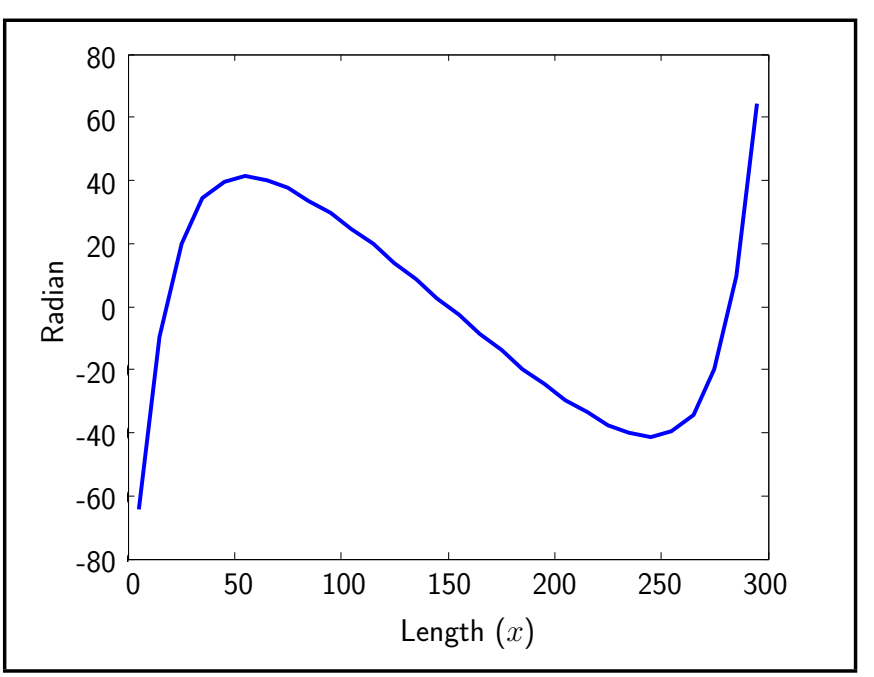

Figure 11. Variation of $\gamma$ along the length of the simply supported beam (first mode).

treatment is applied in the regions $0-40 \mathrm{~mm}$ and $260-300 \mathrm{~mm}$ was 0.027 . This is comparable to the loss factor of $0.03 \mathrm{ob}-$ tained when the damping treatment is applied in the entire region. Therefore, by using the proposed method, the region of damping treatment applications can be better identified, and a better loss factor can be achieved.

\section{CONCLUSIONS}

It is shown that for certain modes of bending vibration the region identified by the maximum strain energy in the viscoelastic layer need not be the suitable location for the efficient application of passive damping treatment. A new approach is proposed in which the region is decided based on parameters, which are the shear strain in the viscoelastic material and the angle of flexure. Regions having significant shear deformation in the viscoelastic layer with the least angle of flexure in the base structure are the most suitable regions. Application of viscoelastic materials in regions identified by the proposed method results in significant loss factor with the least added mass. The methodology has been demonstrated for various boundary conditions. The findings are in good agreement with experimental results. 


\section{ACKNOWLEDGEMENTS}

The authors sincerely acknowledge B. R. Ananda Murthy, H. A. V. Prasad, B. C. Jayakumar, M. Ramesh and other staff of the Post-bonding Lab and Honeycomb Lab in Structures Group at ISRO Satellite Centre for fabricating the test specimens. They are also thankful to Ramesh Naidu, B. R. Nagendra, Bhagiya Lakshmi, and other members at the Shock and Vibration Test Facility for their valuable help in conducting the experimental work.

\section{REFERENCES}

1 Ungar, E.E. Damping of panels. In L. Beranek, editor, Shock and Vibration Handbook. McGraw-Hill, NewYork, 1971.

2 Kerwin, E.M. Damping of flexural waves by a constrained viscoelastic layer. The Journal of the Acoustical Society of America, 31, 952-957, 1959. https://dx.doi.org/10.1121/1.1907821.

3 Taranto, R.A.D. and Balsingame, W. Composite damping of vibrating sandwich beams. Journal of Engineering for Industry, Transactions ASME, 89, 633-638, 1967. https://dx.doi.org/10.1115/1.3610124.

4 Cremer, L., Heckl, M., and Ungar. Structure-borne sound. Springer, 1973.

5 Nokes, D.S. and Nelson, F.C. Constrained layer damping with partial coverage. The Shock and Vibration Bulletin, 38, 5-10, 1968.

6 Dewa, H., Okada, Y., and Nagai, B. Damping characteristics of flexural vibrations for partially covered beam with constrained viscoelastic layers. JSME International Journal, 34, 210-217, 1991. https://dx.doi.org/10.1299/jsmec1988.34.210.

7 Plunkett, R. and Lee, C.T. Length optimization constrained viscoelastic damping. The Journal of the Acoustical Society of America, 48, 150-161, 1970. https://dx.doi.org/10.1121/1.1912112.

8 Johnson, C.D. and Kienholz, D. Finite element prediction of damping in beams with constrained viscoelastic layers. The Shock and Vibration Bulletin, 51, 71-82, 1981. https://dx.doi.org/10.2514/3.51190.

9 Johnson, C.D. and Kienholz, D. Prediction of damping in structure with viscoelastic materials. MSC/Nastran User's Conference Proceedings, 1983.

10 Subramanian, S., Surampudi, R., Thomson, K.R., and Vallurupalli, S. Optimization of damping treatments for structure borne noise reduction. Journal of Sound and Vibration, 38(9), 14-17, 2004. https://dx.doi.org/10.4271/200301-1592.
11 Chia, C.M., Rongong, J.A., and Worden, K. Strategies for using cellular automata to locate constrained layer damping on vibrating structures. Journal of Sound and Vibration, 319, 119-139, 2009. https://dx.doi.org/10.1016/j.jsv.2008.06.023.

12 Ross, D., Ungar, E.E., and Kerwin, E.M. Damping of plate flexural vibrations by means of viscoelastic laminate. Structural Damping, ASME, New york, 20, 49-88, 1959. https://dx.doi.org/10.12691/jmdv-5-1-3.

13 Ioaninides, E. and Grootenhuis, P. A finite element element analysis of the harmonic response of damped three layer plates. Journal of Sound and Vibration, 67, 203-218, 1979. https://dx.doi.org/10.1016/0022-460X(79)90484-X.

$14 \mathrm{Ma}$, B.A. and He, J.F. A finite element analysis of viscoelastically damped sandwich plates. Journal of Sound and Vibration, 152(1), 107-123, 1992. https://dx.doi.org/10.1016/0022-460X(92)90068-9.

15 Lu, Y.P. and Everstine, G.C. More on finite element modeling of damped composite systems. Journal of Sound and Vibration, 69, 199-205, 1980. https://dx.doi.org/10.1016/0022-460X(80)90606-9.

16 Castel, A., Loredo, A., Hafadi, A.E., and Martin, B. Complex power distribution analysis in plates covered with passive constrained layer damping patches. Journal of Sound and Vibration, 331, 2485-2498, 2012. https://dx.doi.org/10.1016/j.jsv.2012.01.020.

17 Shorter, P.J. Wave propagation and damping in linear viscoelastic laminates. Journal of the Acoustical Society of America, 115, 1917-1925, 2004. https://dx.doi.org/10.1121/1.1689342.

18 Mace, B.R., Duhamel, D., Brennan, M.J., and Hinke, L. Finite element prediction of wave motion in structural waveguides. Journal of the Acoustical Society of America, 117, 2835-2843, 2005. https://dx.doi.org/10.1121/1.1887126.

19 Manconi, E. and Mace, B.R. Estimation of the loss factor of viscoelastic laminated panels from finite element analysis. Journal of Sound and Vibration, 329, 3928-3939, 2010. https://dx.doi.org/10.1016/j.jsv.2010.04.014.

20 Johnson, C.D. and Kienholz, D.A. Finite element prediction of damping in structures with constrained viscoelastic layers. AIAA Journal, 20, 1284-1290, 1982. https://dx.doi.org/10.2514/3.51190.

21 Mead, D.J. The measurement of the loss factors of beams and plates with constrained and unconstrained damping layers: A critical assessment. Journal of Sound and Vibration, 300, 744-762, 2007. https://dx.doi.org/10.1016/j.jsv.2006.08.023. 